\title{
SAHALA KEPEMIMPINAN PEREMPUAN DALAM KONTEKS MASYARAKAT BATAK DAN ALKITAB
}

\author{
Riris Johanna Siagian \\ STT - HKBP Pematangsiantar \\ ririsjohannasiagian@gmail.com
}

\begin{abstract}
This study is an effort to explore more concrete and holistic understanding related to existence and woman role in Batak society. In reality, Batak have several terms which refer to the strong existence of woman in Batak society. However, since the lineage is drawn from the male line as the case in patriarchal culture, the strategic roles of women themselves often become neglected. This study conducted a constructive critical study to position women's leadership in the context of Batak community. It began by describing the real conditions of women in the context of Batak community. Furthermore, constructive critical study was carried out by looking at religious literature as well as myth. The use of myths as study material is usually done in the study of the Sciences of Religions, because people believe that myths contain teachings about the moral of a society, which are accepted and lived as a teaching in daily life. Through that, things can also be found to be learning for the future. The study of the Sciences of Religions also uses the the Sociology of Religion to discuss humanity and religion itself. Theological reflection on certain texts in the Bible is carried out with a new perspective. This way is done to rise up the strength of woman. Of course, this study have already finished by a deep and long study, so what is presented here is the result of the researcher recommends only.
\end{abstract}

Key Words: Batak, mythos, sahala, religion, culture and society

Abstrak: Tulisan ini bertujuan menggali pemahaman yang lebih konkrit dan holistik tentang eksistensi dan peran perempuan dalam masyarakat Batak. Dalam kenyataannya, Batak memiliki beberapa istilah yang menunjuk pada eksistensi yang kuat dari kaum perempuan dalam masyarakat Batak. Namun demikian, mengingat garis keturunan ditarik dari garis keturunan laki-laki sebagaimana lajimnya dalam budaya patriarki, maka peran-peran strategis kaum perempuan itu sendiri sering menjadi terabaikan.

Dimulai dengan pemaparan kondisi riil perempuan dalam konteks masyarakat Batak. Selanjutnya telaah kritis konstruktif dilakukan dengan mencermati sastra-sastra keagamaan seperti halnya sebuah mitos. Penggunaan mitos sebagai bahan studi biasa dilakukan dalam studi IImu Agama-agama, karena banyak orang meyakini bahwa mitos memuat ajaran tentang moral suatu masyarakat, yang diterima dan dihidupi sebagai pengajaran dalam hidup sehari-hari. Melalui itu, dapat pula ditemukan hal-hal yang menjadi pembelajaran untuk masa yang akan datang. Kajian IImu Agama-agama juga menggunakan pendekatan Sosiologi Agama untuk membahas tentang manusia dan agama itu sendiri. Refleksi teologis terhadap nats-nats tertentu dalam Alkitab dilakukan dengan perspektif baru, sehingga melalui tulisan ini ditemukan kekuatan lahiriah yang ditampilkan kaum perempuan dari kedalaman jiwanya, sahala-nya. Tentu saja kajian ini telah melewati satu studi yang mendalam, sehingga apa yang dipaparkan di sini bukanlah hasil pemikiran subjektif penulis semata.

Kata Kunci: Batak, mitos, sahala, agama, budaya dan masyarakat. 
Sejarah Batak memerlihatkan bahwa dari dulu hingga saat ini kepemimpinan perempuan dalam konteks Batak sangat kuat dan strategis. Hanya saja masih memang banyak persoalan yang dihadapi di kalangan masyarakat Batak itu sendiri, termasuk di lingkungan lembaga keagamaan. Perempuan masih saja mengalami banyak diskriminasi dan marjinalisasi dalam struktur organisasi dan pengambilan keputusan. Bahkan tidak jarang mengalami kekerasan seksual dari laki-laki yang secara struktural berada di atas.

Salah satu yang menyebabkan persoalan ini adalah penafsiran yang bias atas budaya Batak, yang seolah-olah memberikan hak istimewa kepada laki-laki (Siagian, 2017). Padahal sesungguhnya budaya Batak tidaklah mendiskriminasi atau menyubordinasi kaum perempuan. Konsep sahala, khususnya sahala kepemimpinan perempuan, merupakan sebuah konsep budaya Batak yang menegaskan poisisi perempuan yang setara dengan kaum laki-laki.

Sahala kepemimpinan perempuan Batak bisa ditemukan dalam sastra-sastra keagamaan Batak. Di antaranya yang sangat akrab dengan masyarakat Batak sendiri mitos tentang Si Boru Deak Parujar. Mitos ini memuat filosofi Batak tentang dunia, manusia dan segala sesuatunya. Sebab itu, penulis ingin menggali konsep sahala kepemimpinan perempuan dalam konteks masyarakat Batak yang dimulai dari mitos Batak Si Boru Deak Parujar untuk menegaskan nilai-nilai kesetaraan perempuan terhadap laki-laki. 


\section{METODE}

Pendekatan yang digunakan dalam penelitian ini adalah perbandingan sejarah, yaitu membandingkan sejarah masa lampau dan masa sekarang secara kritis. Dalam hal ini penulis menggali mitos di masa lalu, khususnya mitos Batak Si Boru Deak Parujar, yang melaluinya tradisi masa lampau berkaitan dengan otoritas dapat dipetakan (Harding, Nettleton, \& Taylor, 1990) dan membandingkannya dengan kepemimpinan perempuan di masa kini.

Dari segi jenis data, metode yang digunakan adalah kualitatif, yaitu mencermati realitas konstruksi sosil, makna sejarah, mencermati berbagai peristiwa, menggali nilai, dan lain sebagainya menegaskan ini jenis penelitian kualitatif (Harding et al., 1990).

\section{HASIL}

Kata sahala berasal dari bahasa Batak dan ditemukan dalam beberapa mitos Batak (Tobing, 1963), yang artinya adalah wibawa plus atau karisma plus. Kata ini cukup diminati oleh para misionaris pada masa kekristenan awal di tanah Batak. Bahkan pada tahun 1943 telah pernah terbit majalah bulanan Bataksbond bernama Sahala (Siagian, 2018).

Pada zaman misionaris kata sahala sempat dipahami terkait dengan sipelebegu (penyembah berhala). Hal itu membuat orang-orang yang sudah menjadi Kristen sangat takut jika disebut sipelebegu. Padahal hal itu hanyalah stereotip para misionaris untuk membatasi orang Batak melakukan ritual keagamaan mereka. Seiring perkembangan kegi- 
atan misi, konsep sahala menjadi sesuatu yang kurang diminati (Siagian, 2018).

Belakangan ini, teologi sahala mulai dimunculkan kembali. Orang Batak mulai membicarakan ulang konsep ini. Bukan lagi sebagai konsep yang menakutkan. Bahkan diharapkan perwujudannya dalam diri seseorang. Hal ini bisa ditemukan dalam doa-doa yang disampaikan di tengah-tengah komunitas warga jemaat maupun pelayan gereja.

Dalam diskursus mengenai kepemimpinan perempuan, khususnya dalam konteks masyarakat Batak, munculnya kembali konsep sahala menjadi potensi yang dapat digunakan untuk mencermati peran-peran strategis perempuan, baik di dalam keluarga, gereja, maupun masyarakat.

Dengan kata lain, konsep sahala digunakan sebagai kaca mata baru dan pisau analisis untuk merekonstruksi ulang eksistensi perempuan menurut filosofi Batak. Tidak lupa, tentunya, untuk merefleksikannya secara teologis menurut pandangan Kristen untuk mempertemukan korelasinya dengan kehidupan bergereja.

Sahala kepemimpinan perempuan Batak menunjuk pada Si Boru Deak Parujar. la adalah putri dari Batara Guru, anak sulung dari Mulajadi na Bolon, Tuhan dalam pemahaman keyakinan Batak (Sinaga, 2014). Si Deak Parujar dianggap memiliki sahala yang tinggi luar biasa karena peran-peran strategis dan tanggung jawab yang diembankan kepadanya dan dilakoninya sebagaimana terungkap dalam mitos-mitos Batak.

Sahala memerlihatkan bahwa karakteristik kepemimpinan perempuan tidak berbeda dengan karakteristik kepemimpinan laki-laki Riris Johanna Siagian 
(Siagian, 2019). Makna kata sahala dalam kepemimpinan Batak bersifat universal. Sebab itu, teologi sahala pun dapat digunakan untuk mencermati berbagai persoalan ketimpangan relasi perempuan dan laki-laki.

\section{PEMBAHASAN}

\section{Sahala Kepemimpinan Perempuan Dalam Konteks Masyarakat Batak}

Ada pun sahala, terbentuk atas tiga faktor yang mendasar, yakni: spiritualitas unggul, kualitas unggul, dan karakter unggul.

\section{Spiritualitas Unggul}

Berkontemplasi. Cara membangun spiritualitas yang efektif adalah berkontemplasi. Menurut mitos, manusia pertama diciptakan Mulajadi na Bolon adalah Batara Guru, Soripada, Mangala Bulan. Selanjutnya Mulajadi na Bolon, menciptakan tiga orang perempuan, dan masingmasing darinya menikah dengan putra Mulajadi na Bolon. Mereka pun dianggap dewa/dewi dalam banyak mitos Batak dan tinggal bersama Mulajadi di kayangan. Si Boru Deak Parujar, putri dari Batara Guru, yang oleh Batara Guru hendak dinikahkan dengan putra Mangala Bulan bernama Tuan Ruma Uhir, Tuan Ruma Gorga.

Oleh karena Batara Guru bersikeras dengan rencana pernikahan itu, maka Si Boru Deak Parujar terlebih dahulu meminta waktu untuk diijinkan menenun. Masa itu pun digunakan Si Boru Deak Parujar untuk berfikir dan merenung, ia berkontemplasi untuk satu waktu yang panjang, yakni selama masa 7 tahun 7 bulan (Sinaga, 2014).

Dalam kosmologi Batak, angka memiliki makna khusus. Angka 7 
diyakini merupakan tempat berdiam para dewata di langit na 7 tingka, ombun na 7 lampis (Tampubolon, 2012). Juga bila ada orang tua yang meninggal dunia khususnya yang sudah saur matua, saur matua maulibulung, maka sebelum jasadnya dikubur, terlebih dahulu disimpan di banggar ni jabu (di atas balebale rumah), selama 7 tahun 7 bulan 7 hari 7 malam. Selama itu para keturunannya bergantian membawa dupa sambil mengenang kebaikannya, sahala-nya di masa hidup. Setelah itu baru diadakan ritual yang besar untuk acara penguburannya (Hutagalung, 1963).

Tentu saja waktu itu cukup panjang hingga Si Boru Deak Parujar berhasil menenun semua jenis ulos, sampai gelendong benangnya menjadi sangat kecil. Penenun ulos dahulu (partonun ulos na jolo), melakukan tugas menenun ulos sebagai bagian dari kontemplasi.

Dalam masa itu, setiap tahap proses menenun adalah proses berkomunikasi dengan Mulajadi dan alam semesta. Tidak ada jaminan bahwa sebuah ulos akan dapat selesai ditenun, jika dalam proses kontemplasi dianggap ada hal-hal yang mengganggu. Maka biasanya hal itu harus diselesaikan terlebih dahulu, termasuk melakukan ritual, barulah ulos dapat selesai ditenun. Motif-motif yang dituangkan dalam ulos juga berkaitan dengan hasil kontemplasi (Siagian, 2018). Seperti proses terjadinya penciptaan bumi, manusia dan segala isinya, juga bagianbagian penting dari ritual Batak. Atas dasar itu, Si Boru Deak Parujar dapat disebut sebagai Pencipta tenunan ulos Batak. 


\section{Kualitas Unggul}

Perempuan Terampil - Penenun Ulos

Proses menenun ulos berkaitan dengan kompetensi yang diperlukan untuk mendapatkan ketenangan batin bagi si penenun. Ketenangan batin sangat berguna untuk menghasilkan karya yang indah. Oleh karena itu, selain nilai ekonomi, tenunan ulos juga memiliki nilai seni dan nilai religius.

Hany orang yang terampil yang mampu menenun ulos yang indah. Beberapa penenun ulos di Pulau Samosir mengemukakan bahwa untuk bisa menenun ulos, seseorang harus memiliki daya ingat yang kuat dan kemampuan berhitung secara matematika yang mumpuni sehingga hasil tenunan dapat selesai dengan baik dan indah. Seorang penggiat ulos berkebangsaan Belanda, Sandra Niessen yang begitu mencintai ulos Batak memuji dengan hebat bahwa perempuan Batak sejak dahulu terkenal pintar dan hebat (Siagian, 2018).

\section{Perempuan Berpendidikan - Sibaso (Datu Ina)}

Sebelum kekristenan orang Batak menimba pengetahuan dan pendidikan secara informal. Pada masa itu, perempuan sudah berperan penting. Sibaso (datu ina) merupakan perempuan yang dijadikan tempat belajar atau guru. Biasanya para murid yang diterima belajar oleh Sibaso akan tinggal di rumah gurunya hingga waktu belajarnya selesai. (Siagian, 2018).

Sebagai tokoh dalam masyarakat, Sibaso juga bisa memegang jabatan pemimpin, di samping adanya raja. Sibaso juga adalah imam 
(pemimpin ritual) karena ia bertugas sebagai medium, perantara dalam satu ritual tertentu (Lumbantobing, 1996).

Dengan demikian, sejak awal perempuan dan laki-laki dalam masyarakat Batak telah punya kesempatan dan kemauan yang sama untuk mengecap pendidikan. Begitu juga sama-sama punya tanggung jawab dalam hal kepemimpinan.

\section{Karakter Unggul}

Perempuan Mendatangkan Kehidupan (martondi pangoluhon)

Melalui kepemimpinan si Boru Deak Parujar Nampak bahwa perempuan diciptakan untuk mendatangkan kehidupan. Berdasarkan mitos penciptaan dunia, pada awalnya tidak ada kehidupan di dunia ini. Karena itu Mulajadi, sang pencipta, mengadakan manusia untuk menghuninya sehingga ada kehidupan (Sinaga, 2014).

Berintegritas (Satu Kata dan Tindakan, Sada Hata Nang Pangalaho)

Sikap berintegritas ini juga dimiliki Si Boru Deak Parujar. Hal itu terlihat ketika ia punya kemampuan untuk berkata tidak, untuk apa yang dia tidak setujui yakni ketika ia menolak untuk dinikahkan dengan anak Mangala Bulan bernama Tuan Ruma Uhir, Tuan Ruma Gorga. Seorang pemimpin dianggap memiliki integritas jika apa yang diucapkannya sesuai dengan tindakannya.

Visioner (panatapan tu jolo)

Salah satu kemampuan yang harus dimiliki seorang pemimpin dewasa ini adalah kemampuan melihat sesuatu di depan di mana orang 
lain belum melihatnya. Kemampuan seperti ini sangat diperlukan dalam dunia modern sekarang ini, terutama untuk menbaca situasi dan menemukan peluang dan kesempatan. Kemampuan menjadi seorang yang visioner juga dihasilkan melalui kontemplasi. Dalam proses menenun ulos, Si Boru Deak Parujar memakai kesempatan itu untuk berfikir dan merenung tentang dirinya dan masa depannya, hingga ia memiliki penglihatan (panatapan tu jolo) lewat mimpi tentang apa yang harus diperbuatnya. la mencoba turun ke benua tengah, ketika di sana tidak ada daratan dan ia dihempas-hempaskan oleh gelombang, kemudian ia meminta kepada Mulajadi lewat pesuruhnya agar diberikan tanah.

Si Boru Deak Parujar mulai bekerja untuk menempa tanah dan itu terlihat dengan terbentuknya tanah daratan yang luas dan panjang. Dalam proses menempa daratan itu, ada pula tokoh lain, bernama Naga Padoha yang selalu berusaha menghancurkan daratan yang dibuat dengan tangan Deak Parujar. Setiap kali tanah itu dihancurkan Naga Padoha, segera pula ditempa kembali oleh Deak Parujar.

Penciptaan bumi itu sendiri terjadi atas kuasa dan kehendak Mulajadi, namun pekerjaan itu berlangsung melalui seorang perempuan na marsahala, Si Boru Deak Parujar. Jadi, meski awalnya Si Boru Deak Parujar bersikap menolak rencana bapaknya, dan bahkan rencana itu disetujui oleh Mulajadi na Bolon, namun Mulajadi na Bolon tidak membiarkannya sendiri. la tetap mendengar apa yang disampaikannya dan bahkan memenuhi permintaan-permintaannya. Sikap Mulajadi dalam 
hal ini menunjukkan sikap marorot, melindungi dan mengayomi Si Boru Deak Parujar.

Dalam pemahaman Batak, diumpamakan seperti partataring/ parapi na so haintopan. Kata-kata itu biasa ditujukan kepada seorang pemimpin na marsahala, istilah tataring tempat memasak dalam tradisi Batak, tetapi kata itu sendiri tidak ditujukan kepada perempuan semata. Tetapi pemaknaan kata itu, seperti seorang ibu yang marorot anaknya, ia pun mempersiapkan segala sesuatu yang dibutuhkan anaknya, termasuk memeliharanya untuk bertumbuh menjadi anak yang kuat dan mandiri. Itulah yang harusnya dimiliki seorang pemimpin. Istilah parbahulbahul na bolon sendiri menunjuk pada sikap seorang pemimpin sebagai parorot. la tidak hanya memerintah tetapi berbela rasa atas setiap situasi yang dihadapi orang-orang di dalam wilayah naungannya.

Hingga Si Boru Deak Parujar merasa bahwa daratan itu cukup layak untuk didiami manusia, maka ia pun mulai berdiam di sana (Siagian, 2018). Ini sekaligus merealisasikan kehendak Mulajadi na Bolon agar ada manusia mendiami bumi. Kemudian atas kehendak Mulajadi, la pun mengirim putra Mangala Bulan, Tuan Ruma Uhir, Tuan Ruma Gorga ke dunia tengah. Dalam satu momen, kemudian Tuan Ruma Uhir, Tuan Ruma Gorga kemudian mendatangi tempat tinggal Si Boru Deak Parujar. Atas kehendak Mulajadi na Bolon keduanya menikah dan hidup bersama. Hal ini sekaligus menunjukkan peran perempuan yang besar dalam membangun rumah tangganya dan membuat segala sesuatunya cukup. 
Dapat Dipercaya (Haposan)

Dari sini kita bisa melihat bahwa perempuan Batak itu terbilang seorang pekerja keras dan tidak mudah putus asa. Sebagaimana Deak Parujar, ada satu spirit bahwa apa yang dia kerjakan harus selesai dengan baik, berhasil. Dia berupaya memenuhi tanggung jawab yang telah diembankan kepadanya.

Untuk dapat menjadi seseorang yang marorot, maka ia sendiri harus dapat meyakinkan orang-orang yang dipimpinnya. Kata-kata dan tindakannya sendiri harus mampu menciptakan satu keyakinan pada orang di sekitarnya, bahwa ia layak dipercaya (haposan). Istilah sitiop puro (bendahara), biasa dikenakan kepada perempuan. Tetapi dalam kenyataannya, istilah sitiop puro juga disandang laki-laki yang dipilih sebagai bendahara di tengah-tengah masyarakat dan gereja Batak. Namun adakah syarat seseorang untuk diangkat menjadi sitiop puro? Sifat dan karakter ini juga menunjuk pada perilaku Soripada, adik laki-laki dari Batara Guru.

Ada pun sifat khas dari Soripada, ia dipandang sebagai "seorang yang dapat dipercaya, orang jujur dan selalu benar; tidak mencuri dan tidak pernah kecurian, tidak makan sogokan," (Tobing, 1963, p. 27). Sifat -sifat ini sekaligus menunjuk pada sifat Batak untuk bersikap sebagai orang yang dapat dipercaya (haposan).

\section{Refleksi Teologis: Sahala Kepemimpinan Perempuan dalam Alkitab}

Selain legitimasi budaya, ketidakadilan yang dialami oleh kaum perempuan juga dilegitimasi oleh penafsiran yang bias terhadap ayat- 
ayat tertentu dalam Alkitab. Oleh karena itu, penting pula untuk menggali sahala kepemimpinan perempuan yang ada dalam Alkitab untuk memperkuat landasan teologis bagi kesetaraan perempuan dan laki-laki. Dua tokoh perempuan yang menarik untuk dikaji adalah Ester dan Rut.

\section{Spiritualitas Unggul}

Sahala muncul dan bertumbuh subur dalam hubungan yang intens dengan Tuhan. Ketika menghadapi tekanan yang sulit, Ester menyerukan kepada seluruh bangsa Yahudi yang ada dalam kerajaan agar berdoa dan berpuasa, serta melakukan ritual berkabung. Bahkan ia sendiri memimpin langsung ritual berkabung itu di dalam Benteng Susan dan istana kerajaan (band. Est. 4:1).

Demikian juga Rut. Ketika Naomi memutuskan kembali ke Israel, Rut bersikeras untuk ikut (Rut 1:16). Perempuan Moab ini yang sebelumnya tidak mengenal Tuhan Allah tetapi berubah menjadi begitu kuat memegang tradisi kepercayaan Israel. Tanda suatu kualitas spiritual yang unggul yang terwujud dalam cinta kasih kepada mertua dan bangsanya (Rut 1:16-17). Sejatinya, cinta kasih itulah yang mendorong loyalitas diperlihatkan dengan kesiapan membela perkara orang yang dihormati, dan sikap tunduk pada perintahnya. Kerangka berfikir demikian merupakan satu bagian dari kepemimpinan karisma (Weber, 2006) di mana loyalitas benar-benar diperlihatkan pada sosok pemimpin yang dipuja.

\section{Kualitas Unggul}

Hal ini berkaitan dengan kemampuan-kemampuan atau kualitas 
tertentu yang dimiliki seseorang dalam perannya sebagai seorang pemimpin. Melalui Kitab Ester dicermati bahwa sebagai ratu, Ester memahami benar situasi dan kondisi di wilayah kerajaan, termasuk psikologis orang yang dihadapinya, yakni Raja Ahasyweros. la juga memiliki perhitungan yang cermat, tepat dan matang. Ini sekaligus menegaskan pentingnya ilmu psikologi dan analisa sosial yang cermat dalam pelayanan gereja sehari-hari.

Meski telah 30 hari tidak dipanggil menghadap oleh raja (Est. 4:11), tetapi ia sendiri menyiapkan dirinya untuk dipanggil raja dengan cara tampil di pelataran dalam istana raja dengan menggunakan pakaian kebesaran ratu (Est. 5:1). Ester juga memahami betul bagaimana harus memikat hati raja dan berhasil (Siagian, 2019). Keindahan tubuhnya dan kecantkan wajahnya tidak digunakan untuk menguntungkan dirinya sendiri. Tetapi hal itu dipandang sebagai satu karunia khusus dan digunakan untuk menghadirkan keselamatan bagi bangsanya. Itu terjadi ketika kemudian Raja Ahasyweros mengulurkan tongkat emasnya (Est. 5:4-8). Bahkan raja begitu jatuh cinta meluap-luap pada Ester hingga raja berjanji akan memenuhi keinginan Ester meski harus memberi setengah dari kerajaan (Est. 5:4-8).

\section{Karakter Unggul}

Di sini, spiritualitas dan kualitas unggul yang dimiliki Ester menjadi faktor yang sangat kuat dalam membentuk karakter unggul yang dimiliki. Satu hal mendasar yang menguatkan Ester untuk menghadap Raja Ahasyweros adalah kekuatan doa yang membentengi dan mengawal 
sendiri, ia memiliki team work, ia bekerja sebagai satu tim dengan seluruh orang Yahudi dan Mordekhai untuk satu tujuan besar itu, penyelamatan hidup bangsa Yahudi.

Satu hal yang paling menonjol adalah perilaku tulus hati dan penuh cinta kasih. Ketulusan hati Ester untuk menyelamatkan banyak orang, bangsanya sendiri, bangsa Yahudi membuktikan cinta kasihnya pada bangsanya. Kecintaan Ester pada bangsanya melampaui kecintaan Ester pada dirinya sendiri. Dalam cintanya yang luar biasa, Ester berupaya taat pada panggilan untuk mengayomi bangsanya. Ester memiliki jiwa patriotisme sejati. la adalah pejuang sejati (Siagian, 2019). la adalah pemimpin sejati. Sebagai seorang pemimpin sifat mengayomi (marorot) jelas diperlihatkan. Sebagai seorang ratu, Ester memiliki karakter yang sangat kuat dan unggul dan menegaskan dirinya sebagai partogi (pemimpin), pargomgom (pelindung).

Cinta dalam kesetiaan dan ketaatan demikian juga ditemukan dalam diri Yesus Kristus yang rela mati karena cinta kasih-Nya pada manusia dan ketaatan-Nya pada Bapa-Nya di sorga (Yoh. 3:26). Kematian Yesus di kayu salib dan bangkit kembali dari antara orang mati sekaligus memproklamirkan ketaatan yang sempurna dari seorang Anak kepada Bapa. Oleh karena itu, Yesus yang sebelumnya diejek, dihakimi dunia, dicemooh kemudian mati dan bangkit dan naik ke sorga sebagai Raja Agung, penuh cahaya kemuliaan, penuh sahala.

Dapat saja muncul tudingan bahwa Ester memakai kesempatan itu untuk merebut hati raja dan mendapat jabatan sebagai permaisuri raja Ahasyweros. Pada saat yang sama ia menyingkirkan Wasty. Memang 
Alkitab tidak menjelaskan lebih jauh tentang Wasty. Namun pengenalan atas Ester yang memiliki spiritualitas yang unggul dan penuh cinta kasih sebagaimana diperlihatkannya pada bangsa Yahudi, sangat mungkin ia pun penuh cinta kasih pada Wasty dan mempersiapkan tempat yang terbaik bagi Wasty. Dari sini sekaligus dapat diamati bahwa Ester menjadi ratu untuk satu tujuan yang sangat besar yakni penyelamatan bangsa Yahudi dan itu berlangsung melalui Mordekhai, Ahasyweros dan Ester sendiri.

Batak juga memiliki beberapa tokoh perempuan yang sudah teruji sahala-nya seperti: Julia Sarumpaet, seorang pendidik dan aktifis dari Toba. Sebagai ketua PWKI, dia yang pertama bicara di Sinode Godang HKBP dan memerjuangkan agar perempuan mendapat tempat dalam seluruh pelayanan gereja (Sarumpaet, 1998). Maria Siregar merupakan tokoh perempuan Batak pertama yang mengajarkan pendidikan bagi perempuan Batak dan pendiri "Sikola Agong," dan diangkat sebagai anak oleh I. L. Nommensen (Siagian, 2018). Putri Lopian, merupakan kesayangan dari Sisingamangaraja yang berjuang melindungi tanah Batak dari penjajahan pemerintah kolonial. Sang Putri Lopian yang meninggal di tengah hutan ketika berupaya melindungi ayahnya Raja Sisingamangaraja dalam perang Batak dan banyak lainnya.

\section{Tindak Lanjut}

Dengan demikian, beberapa hal yang perlu mendapat penajaman untuk peningkatan kehadiran pemimpin-pemimpin perempuan Batak dalam gereja dan masyarakat di masa yang akan datang antara lain: 


\section{Pembangunan Karakter}

Pembangunan karakter merupakan satu proses yang harus terusmenerus dilakukan. Dapat saja sebuah aturan terlihat baik tetapi di tahap implementasi buruk. Ini tidak lepas dari karakter orang-orang yang menjalankan aturan itu, bahkan penyusunan aturan yang baik sangat terkait dengan sumber daya dan karakter orang-orang yang menyusunnya. Apakah substansi implementasi aturan gerejawi memerlihatkan kemuliaan Kristus sebagai Kepala Gereja atau lebih terlihat sebagai satu sistim organisasi yang mengatur banyak orang. Gereja-gereja perlu mendesain program-program pengembangan spiritual, seperti retreat dan meditasi dan memfasilitasinya.

\section{Perempuan Harus Berpendidikan}

Untuk itu, perempuan harus bersekolah, formal dan informal. Sejarah Batak telah membuktikan bahwa pendidikan merupakan pintu utama memahami Tuhan, dunia dan sesama manusia dan pada gilirannya memiliki sahala.

\section{Membangun Jaringan}

Perempuan perlu memiliki jaringan yang kuat dan team work serta saling bersinergis. Jaringan yang kuat akan membuat gerak perempuan muncul kepermukaan.

\section{Membangun Partnership}

Sejarah tokoh-tokoh Alkitab membuktikan bahwa perempuan berhasil tidak pernah hanya dengan kekuatannya, tetapi saling bersiner- 
gis dengan kaum laki-laki. Ester dan Mordekhai sudah membuktikannya. Sampai di titik ini, apakah karakteristik kepemimpinan perempuan berbeda dengan laki-laki? Faktanya, sahala yang dimiliki oleh laki-laki juga dimiliki oleh perempuan dan sebaliknya. Hanya ketika seseorang mampu menghadirkan dirinya sebagai satu pribadi yang tangguh dan berkarakter unggul, kepadanya patut disebut pemimpin. Dengan kata lain, hal ini menegasan perlunya kompetensi untuk berkompetisi.

\section{KESIMPULAN}

Dari pemahaman di atas menjelaskan bahwa sahala kepemimpinan perempuan dalam konteks masyarakat Batak sangat kuat dan mengakar. Kekuatan yang dimiliki perempuan juga sejajar dengan kekuatan laki-laki. Untuk menjadi seorang pemimpin yang memiliki sahala, wibawa plus atau karisma plus, maka seseorang harus menghidupi pengajaran tentang moral yang terdapat dalam agama yang diyakini. Otoritas yang dimiliki seorang pemimpin adalah bertujuan untuk menyejahterakan banyak orang, dan sebagai alat untuk mendatangkan kehidupan. Untuk itu otoritas itu harus dijalankan dengan cara yang benar dan bermartabat.

Kepemimpinan menjadi rentan konflik bila dilakukan secara tidak tepat. Bahkan perempuan yang berada dalam tataran pengambilan keputusan pun tidak dapat berbuat apa-apa, jika ia gagal fokus. Jika demikian, kepemimpinan akan menjadi sangat mengkuatirkan dan rakus. 
Kehidupan Batak dan penghayatan kekristenan memerlihatkan bahwa di dalam diri setiap orang dapat terbentuk sahala karena tiga hal: spiritualitas unggul, kualitas unggul, karakter unggul. Implementasi dari ketiganya akan menghasilkan sahala sebagai substansi tertinggi dari setiap agama, dalam hal ini Batak dan Kristen. Perubahan orientasi dari sahala kepada kuasa mengakibatkan hilangnya keheningan batin dan pudarnya kebeningan berfikir. Implementasi kuasa pun selalu berakhir dengan perolehan jabatan dan uang.

Meski begitu, berbagai tindak kekerasan pun terjadi akibat hilangnya nilai-nilai yang ideal dalam diri manusia itu sendiri, seperti: komitmen, integritas, penghargaan terhadap sesama, dan lain sebagainya. Keheningan batin dapat diperoleh melalui perenungan dan kontemplasi.

Dengan demikian, keluarga menjadi tempat ideal terutama untuk menanamkan nilai-nilai tersebut. Pelayanan yang baik kepada warga jemaat, terutama untuk sekolah Minggu, remaja, dan pemuda sangat menolong untuk menanamkan nilai-nilai tersebut melalui gereja. Diharapkan lahir orang-orang yang memiliki karakter unggul di masa depan dan menjadi pemimpin gereja, masyarakat dan bangsa ini.

\section{DAFTAR PUSTAKA}

Harding, G., Nettleton, S., \& Taylor, K. (1990). Social Research Methods. In Sociology for Pharmacists. https://doi.org/10.1007/978-1-34921149-4_10

Hutagalung, W. (1963). Adat Pardongansaripeon. Medan: NV Pustaka.

Lumbantobing, A. (1996). Makna Wibawa dan Jabatan dalam Gereja Batak. Jakarta: BPK Gunung Mulia. 
Sarumpaet, R. K. T. (1998). Perempuan di Rumah Tuhan. Jakarta: PERSETIA.

Schumann, O. H. (2015). Pendekatan pada IImu Agama-Agama. Jakarta: BPK Gunung Mulia.

Siagian, R. J. (2017). Gereja dan Kekuasaan: Menuju Eklesiologi HKBP yang Kontekstual. Pematangsiantar: Lembaga Bina Warga HKBP dan Sekolah Pendeta HKBP.

Siagian, R. J. (2018). Sahala Bagi Pemimpin: Dulu dan Kini (4th ed.). Pematangsiantar: Lembaga Bina Warga HKBP dan STT- HKBP dan Sekolah Pendeta HKBP.

Siagian, R. J. (2019). Agama, Spiritualitas Kepemimpinan, Gereja dan Masyarakat. Pematangsiantar: Lembaga Bina Warga HBP dan Sekolah Pendeta HKBP.

Sianipar, F. H. (1978). Barita ni Ompu i Justin Sihombing. Pearaja: Kantor Pusat HKBP.

Sidjabat, W. B. (1982). Ahu Sisingamangaraja. Jakarta: Sinar Harapan.

Sinaga, A. B. (2014). Allah Tinggi Batak Toba. Yogyakarta: Kanisius.

Tampubolon, R. P. (2012). Pustaha Tumbaga Holong: Adat Batak: Patik - Uhum (3rd ed.). Jakarta: Dian Utama dan Kerabat (Kerukunan Masyarakat Batak).

Tobing, P. L. (1963). The structure of the Batak Toba belief in the high God. (2nd ed.). Amsterdam: South and South East Celebes Institute For Culture.

Weber, M. (2006). Essay in Sociology. New York: Oxford University Press.

Weber, M. (2019). Economy and Society. In Economy and Society (2nd ed.). https://doi.org/10.4159/9780674240827

Winter, G. (2013). Sociology of Religion. In Journal of the American Academy of Religion. https://doi.org/10.1093/jaarel/xl.1.118 